\title{
Prevalence of Depression and Anxiety Disorders in People Living with HIV/AIDS in a Tertiary Hospital in South Western Nigeria
}

\section{Adekunle Olatayo Adeoti ${ }^{1^{*}}$, Mobolaji Usman Dada ${ }^{2}$ and Joseph Olusesan Fadare ${ }^{1}$}

${ }^{1}$ Department of Medicine, Ekiti State University Teaching Hospital, Ado-Ekiti, Ekiti State, Nigeria

${ }^{2}$ Department of Psychiatry, Ekiti State University Teaching Hospital, Ado-Ekiti, Ekiti State, Nigeria

*Corresponding author: Adekunle Olatayo Adeoti, Department of Medicine, Ekiti State University Teaching Hospital, Ado-Ekiti, Ekiti State, Nigeria, Tel: +2348035017228; E-mail: Kadeoti2002@yahoo.com

Received Date: Jan 04, 2018; Accepted Date: Feb 10, 2018; Published Date: Feb 20, 2018

Copyright: $\odot 2017$ Adeoti AO, et al. This is an open-access article distributed under the terms of the Creative Commons Attribution License, which permits unrestricted use, distribution, and reproduction in any medium, provided the original author and source are credited.

\begin{abstract}
Background: In sub-Saharan Africa, HIVIAIDS constitutes a major burden with its attendant mental health related challenges. The aim of this study was to determine the prevalence of depression and anxiety disorder among HIV patients attending a tertiary institution in south western Nigeria.
\end{abstract}

Method: A cross-sectional study conducted among HIV patients attending HIVIAIDS clinic of the Ekiti State University Teaching Hospital, Ado-Ekiti, Nigeria. A semi-structured questionnaire was administered to collect sociodemographic characteristics with the incorporation of Hospital anxiety depression questionnaire to assess the prevalence of depression and anxiety in the study and control groups.

Results: A total of 424 HIV positive study participants were recruited. A corresponding age and sex matched 429 control subjects were also enrolled. The mean age of HIV positive patients and controls are $42.2 \pm 9.5$ years and $43.4 \pm 12.4$ years respectively. There was a female prepondence among both study populations. The prevalence of depression among PLHIV was $39.6 \%$ whereas depression was lower in the $(22.0 \%)$ control group. Likewise anxiety was reported in PLHIV and control group as $32.6 \%$ and $28.7 \%$ respectively. Female gender, illiteracy, being divorced/widowed, unemployed and low income and low CD4 count were associated with depression while factors associated with anxiety disorder included lower age, female gender, low income, and low CD4 count.

Conclusion: The prevalence of depression and anxiety are high in the HIV patients, hence proper integration of mental health care into the HIV programme is inevitable to give patients holistic care.

Keywords: Prevalence; Depression; Anxiety; HIV/AIDS; Antiretroviral treatment; PLHIV

\section{Introduction}

HIV/AIDS is a disease of major global concern with significant burden in sub-Saharan Africa. It is globally estimated that 36.7 million people are living with HIV (PLHIV) in 2016, of which 1 million people died of AIDS and 1.8 million new infections in the same year [1]. PLHIV often suffer from depression and anxiety as they adjust to the impact of the diagnosis and face the difficulties of living with a chronic life-threatening illness, of which cure is yet to be discovered [2].

Depression is the commonest psychiatric syndrome reported in PLHIV, however, the majority of the patients with depressive symptoms also had prominent anxiety symptoms and fulfilled the ICD-10 criteria for generalized anxiety disorder [3]. Adjustment disorder is the most common psychiatric disorder that manifests as anxiety, and is common after receiving an HIV diagnosis. Anxiety disorders are a serious concern for PLHIV with poor coping strategies and social support network, such as family, friends, or a faith community [4]. The prevalence of depressive illness among PLHIV on antiretroviral therapy in sub-Saharan Africa is estimated to range from 29 to $63.1 \%$ [5-9].
The prevalence of anxiety disorders among PLHIV as reported in another study in Nigeria was $21.7 \%$ while mixed anxiety and depression was $5.3 \%$ [10]. However, the overall prevalence of psychiatric disorders was reported to be as high as $59.1 \%$ among PLHIV [11].

Various risk factors for developing these psychiatric disorders among these patients have being reported in Africa and these include low income, perceived stigma of the infection, poor level of social support, stage of the disease, unemployment, being unmarried, females, low level of formal education and comorbid opportunistic infections [8-11]. These comorbid states have dual relationships with HIV/AIDS which could affect patients' adherence to antiretroviral drugs, quality of life and life expectancy $[11,12]$.

There is however paucity of data on the burden of mental health problems among PLHIV in Nigeria and no studies investigating this key aspect in the management of PLHIV in Ekiti State. Most of the available studies focused only on depressive illness, others had no control group and relatively small sample size [10,11]. Hence, this study aimed at determining the prevalence of depression and anxiety among PLHIV comparing the findings with age and sex matched control who are HIV sero-negative patients. 


\section{Materials and Methods}

\section{Study design}

A Hospital based cross-sectional study which was conducted among patients accessing care for HIV infection in Ekiti State University Teaching Hospital (EKSUTH). The hospital is located in Ado-Ekiti, Ekiti state situated in the south western region of Nigeria. Ekiti state is located within $7^{\circ} 40^{\mathrm{I}} \mathrm{N} 5^{\circ} 15^{\mathrm{I}} \mathrm{E}$ with an estimated population of $2,384,212$ as at 2006 population census [13].

\section{Study population}

Adult HIV patients on follow up who were diagnosed of this infection and have been on treatment for at least 6 months were recruited for the study. The HIV patients receive treatment at the Medical Outpatient Department where specialists in HIV medicine regularly attend to them like other medical cases. Critically ill patients and non-consenting individuals were excluded from the study. Another group of HIV negative who consented to HIV screening, attending the General Outpatient Department (GOPD) served as control were age and sex matched [14].

\section{Sampling size calculation}

The sample size was calculated using the online statistical software from Raosoft Incorporated. The estimated sample size was 327 from a population of $2150 \mathrm{HIV}$ patients in our facility, using $50 \%$ as response distribution. Twenty percent of the calculated sample size was added to account for incompletely filled questionnaires thereby making a total of 392. We further increased this number to 424 to increase the power of the study.

\section{Survey instrument}

A pretested semi-structured questionnaire was administered by two research assistants who obtained information on socio-demographic profile, stigmatization, suicidal ideation, medication use, HIV screening results. In addition, the Hospital Anxiety Depression scale was used to assess the prevalence of this condition. The same instrument was administered to an unexposed age and sex matched group, who were HIV negative, who presented at the general outpatient department for treatment. The HADS consists of 14 items; the anxiety (HADS-A) and depression (HADS-D) subscales each include 7 items. It has been validated for use as a screening tool for depression and anxiety disorders in general medical outpatient clinics and widely used in clinical practice and research $[15,16]$.

\section{Statistical analysis}

Obtained data were analysed using SPSS statistical software version 20 (SPSS Inc., Chicago, IL, USA). Descriptive statistics were initially used to explore the data and to present results of prevalence and sociodemographic data. Categorical variables were expressed in proportions while continuous variables in mean (standard deviation). A comparison of categorical variables was done using Pearson's Chisquare test while student's t-test was used for comparing continuous variables. A p-value of less than 0.05 was considered statistically significant.

\section{Ethical considerations}

Ethical approval to conduct the study was obtained from the institution's ethics and research committee. Informed verbal and written consent was obtained from every participant and they were ensured of the anonymity and confidentiality by assigning numerical codes to each questionnaire. HIV/AIDS patients found to have depression and anxiety were referred to the psychiatrist's clinic for further evaluation.

\section{Results}

\section{Sociodemographic characteristics}

A total of 424 HIV positive patients were recruited with a corresponding age and sex matched control group of 429 HIV negative patients. The mean age of the HIV positive patients was $42.2 \pm 9.5$ years while the control group was $43.4 \pm 12.4$ years. There was a female preponderance in both the exposed and control groups as the male to female ratios were 1 to 2.8 and 1 to 1.8 respectively. A major percentage $(76.2 \%)$ of HIV positive patients were married and likewise (68.1\%) in the control group. More than half of the respondents in both the HIV positive and control were self-employed $(61.1 \%$ and $50.1 \%$ respectively).

Almost two thirds (63.4\%) of the HIV positive patients had a monthly income less than 140 dollars while just about half (52.4\%) of the control group had a monthly income less than 140 dollars. Only $16.9 \%$ and $14.2 \%$ of the HIV positive patients and control group respectively had no formal education as shown in Table 1 .

\begin{tabular}{|c|c|c|c|c|}
\hline Variable & HIV n (\%) & Control n (\%) & Test/chi ${ }^{2}$ & $p$-value \\
\hline Age $($ mean $\pm S D)$ & $42.16+9.537$ & $43.37+12.380$ & $t=-1.598$ & 0.11 \\
\hline \multicolumn{5}{|l|}{ Sex } \\
\hline Male & $111(26.2)$ & $154(35.9)$ & \multirow{2}{*}{$\operatorname{chi}^{2}=0.347$} & \multirow{2}{*}{0.556} \\
\hline Female & $313(73.8)$ & $275(64.1)$ & & \\
\hline \multicolumn{5}{|l|}{ Marital status } \\
\hline Single & 45 (10.6) & $90(21)$ & \multirow{3}{*}{$\mathrm{chi}^{2}=22.352$} & \multirow{3}{*}{$<0.0001$} \\
\hline Married & $323(76.2)$ & $292(68.1)$ & & \\
\hline Divorce & $28(5.9)$ & $11(2.6)$ & & \\
\hline
\end{tabular}


Citation: Adeoti AO, Dada MU, Fadare JO (2018) Prevalence of Depression and Anxiety Disorders in People Living with HIVIAIDS in a Tertiary Hospital in South Western Nigeria. Med Rep Case Stud 3: 150. doi:10.4172/2572-5130.1000150

Page 3 of 5

\begin{tabular}{|c|c|c|c|c|}
\hline Widow (er) & $31(7.3)$ & $36(8.4)$ & & \\
\hline \multicolumn{5}{|l|}{ Occupation } \\
\hline Civil servant & $131(30.9)$ & $129(30.1)$ & \multirow{4}{*}{$\mathrm{chi}^{2}=30.859$} & \multirow{4}{*}{$<0.0001$} \\
\hline Retired & $7(1.7)$ & $38(8.9)$ & & \\
\hline unemployed & $27(6.4)$ & $47(11.0)$ & & \\
\hline Self employed & $259(61.1)$ & $215(50.1)$ & & \\
\hline \multicolumn{5}{|l|}{ Education } \\
\hline Primary & $68(16.0)$ & $60(14.0)$ & \multirow{4}{*}{$\mathrm{chi}^{2}=15.116$} & \multirow{4}{*}{0.002} \\
\hline Secondary & $144(34.0)$ & $105(24.5)$ & & \\
\hline Tertiary & $197(46.5)$ & $252(58.7)$ & & \\
\hline None & $4(0.9)$ & $1(0.2)$ & & \\
\hline \multicolumn{5}{|c|}{ Average monthly income } \\
\hline$<140$ dollars & $269(63.4)$ & $225(52.4)$ & \multirow{3}{*}{$\mathrm{chi}^{2}=8.887$} & \multirow{3}{*}{0.012} \\
\hline $140-280$ dollars & $86(20.3)$ & $77(17.9)$ & & \\
\hline$>280$ dollars & $12(2.8)$ & $28(6.5)$ & & \\
\hline
\end{tabular}

Table 1: The socidemographic characteristics of the study and control groups.

\section{Clinical characteristics}

Most (70.3\%) of the HIV positive patients are currently on antiretroviral (TDF+3TC+EFV) medication combination. More than half of the HIV seropositive patients had been on the antiretroviral medications for a period of 6 to 10 years. However, very few of the respondents were on antiretroviral medications for 5 years and below as shown in Figure 1.

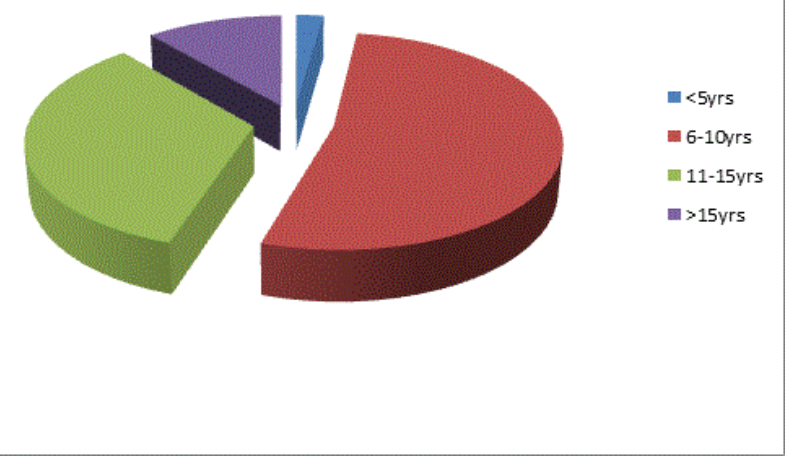

Figure 1: Pie chart of duration on antiretroviral medication.
The median CD4 count of the patients at diagnosis was 224.0 cells/ul with interquartile range (IQR) of 110.5 to 400 cells/ul. A remarkable increase in median current CD4 count to 405.0 cells/ul (IQR 266.0 to 575 cells/ul) was observed and with a median viral load of 42.0 (IQR 20.0 to 555.0 ).

About a third of the exposed group was unaware of their spouses' HIV status and among those that knew, $79.8 \%$ of them had HIV negative partners. Serodiscordant couples constituted a major percent $(79.8 \%)$ of the married respondents while seroconcordant couples were $20.2 \%$.

\section{Psychiatric morbidity}

The prevalence of depression among the HIV positive patients and control group was $39.6 \%$ and $22.0 \%$ respectively $(\mathrm{p}<0.001)$. However, the prevalence of anxiety disorder was $32.6 \%$ and $28.7 \%$ among the exposed and control groups respectively $(\mathrm{p}>0.219)$. The co-existence of both anxiety and depression in HIV positive patients and control was $21.9 \%$ and $14.5 \%$ respectively as shown in Table 2 .

More of cases of depression were reported in females $(42.5 \%$ of females compared to $31.5 \%$ of males) ( $\mathrm{CI}=0.009-0.132)$. Married HIV positive patients had the least proportion (37.2\%) of depression whereas the highest proportion of depression was found among widows (58.1\%) followed by divorced patients (48.0\%). These differences were found to be significant with $\mathrm{p}$ value of 0.03 . 


\begin{tabular}{|c|c|c|c|c|}
\hline Variable & Depression Test & $p$ value & Anxiety Test & $p$ value \\
\hline Age & $\mathrm{T}$ test $=-0.769$ & 0.442 & $\mathrm{~T}$ test $=1.972$ & $0.049^{*}$ \\
\hline Sex & $\mathrm{Chi}^{2}=4.115$ & $0.043^{*}$ & $\mathrm{Chi}^{2}=6.986$ & $0.008^{*}$ \\
\hline Marital status & $\mathrm{Chi}^{2}=5.986$ & $0.03^{*}$ & $\mathrm{Chi}^{2}=1.001$ & 0.801 \\
\hline Educational level & $\mathrm{Chi}^{2}=13.710$ & $0.003^{*}$ & $\mathrm{Chi}^{2}=1.150$ & 0.765 \\
\hline Occupation & $\mathrm{Chi}^{2}=13.768$ & $0.003^{*}$ & $\mathrm{Chi}^{2}=2.663$ & 0.446 \\
\hline Income & $\mathrm{Chi}^{2}=8.101$ & $0.017^{*}$ & $\mathrm{Chi}^{2}=6.205$ & $0.045^{\star}$ \\
\hline Known HIV of partner & $\mathrm{Chi}^{2}=13.981$ & $0.001^{*}$ & $\mathrm{Chi}^{2}=0.283$ & 0.595 \\
\hline HIV status of partner & $\mathrm{Chi}^{2}=2.168$ & 0.338 & $\mathrm{Chi}^{2}=5.180$ & 0.075 \\
\hline Comorbidity & $\mathrm{Chi}^{2}=9.000$ & 0.061 & $\mathrm{Chi}^{2}=9.000$ & 0.061 \\
\hline Viral load & Corr coef $=0.004$ & 0.955 & Corr coef $=-0.065$ & 0.372 \\
\hline CD4 COUNT at diagnosis & Corr coef $=0.044$ & 0.383 & Corr coef $=-0.55$ & 0.275 \\
\hline Current $\mathrm{CD} 4$ count & Corr coef $=-0.166$ & $0.001^{*}$ & Corr coef $=-0.102$ & $0.043^{*}$ \\
\hline
\end{tabular}

Table 2: Factors associated with depression and anxiety disorder.

Almost all the retired HIV positive patients (71.4\%) had depression as opposed to those who were still gainfully employed ( $\mathrm{p}$ value $=0.003$ ). Similarly, HIV infected patients without formal education and only primary education had high rates of depression $(100.0 \%$ and $51.5 \%$ respectively) ( $\mathrm{p}$ value $=0.003$ ).

Depression was also associated with lower socioeconomic class (less than $\$ 140 /$ month) as assessed with monthly income with $p$ value $=0.017$, insomnia $(\mathrm{p}<0.0001)$, low current CD4 count ( $\mathrm{p}$ value $=0.001)$, unaware of spouses' HIV status $(\mathrm{P}<0.001)$ and having thoughts of suicide $(\mathrm{p}<0.0001)$.

In contrast, female sex ( $\mathrm{P}$ value $<0.008)$, lower age of respondents $(\mathrm{P}$ value $<0.049$ ), presence of insomnia ( $\mathrm{P}$ value $<0.0001)$, low income $(\mathrm{P}$ value $<0.045$ ), and low current $\mathrm{CD} 4$ count $(\mathrm{P}$ value $<0.043)$ were significantly associated with anxiety disorder among HIV positive patients in this study.

\section{Discussion}

This study found a higher prevalence of depression and anxiety disorders among HIV patients compared to the controls as well as a higher prevalence of comorbid occurrence of both conditions in HIV patients.

Previous studies have reported similar prevalence of $29.0 \%$ and $40.0 \%$ for depression and $21.7 \%$ for anxiety disorders among HIV patients $[6,7,10]$. However prevalence as high as $63 \%$ and $77.1 \%$ has been reported among HIV patients in other studies [9,16]. This calls for a proper integration of mental health services in HIV care so as to address the prevailing psychosocial needs of PLHIV as they adapt to the challenge of living with a chronic and at the moment uncurable disease.

Similarly, we found a higher prevalence rate of $21.9 \%$ for comorbid anxiety and depression in this study among HIV positive patients compared to a rate of $14.5 \%$ among the controls. The prevalence rate among the HIV positive patients was far higher than a prevalence rate of 5.3\% reported in another study in this environment [10]. However, similar prevalence has been reported in another study [8]. The differences in the various prevalent rates may be due to the different diagnostic tools, sample size variations and different locations of the study.

In this study, depression and anxiety were more common among females. This was also reported by other researchers $[8,9,17,18]$. Marriage as observed in this study appeared to be protective against depression but not against anxiety disorder, as fewer proportion of married HIV positive patients had depression compared to those who were divorced or widowed. Similar studies have also reported that being unmarried or divorced were risk factors for psychiatric morbidity among HIV patients [8,10]. Possible reasons for the high rate especially among divorced respondents include low selfconfidence and possible financial problems [19]. Furthermore, the loss of a close confidant and possibly poor social support system could be responsible for the level of depression among the widowed and divorced. On the contrary, Elbadawi et al. reported high psychiatric morbidity in married HIV patients [9].

The emotional burden associated with low income could be responsible for the reported depression and anxiety in our study. Most of the respondents earned less than two dollar per day and they could be faced with the challenge of meeting financial obligations [20].

Illiteracy was another factor found to be associated with depression but not anxiety disorder. Other studies have also reported similar findings $[9,21]$. Our study found that the unemployed and retired patients had the highest rate of depression. This was collaborated by other studies who reported that unemployment was a risk factor for psychiatric morbidity among HIV patients [10,22].

This study found that lower age of respondents was a possible risk factor for anxiety disorder but not for depression. Younger age as a risk factor for psychiatric morbidity was also reported by other researchers $[10,22]$. The current CD4 count as opposed to the CD4 count at diagnosis was inversely correlated with depression and anxiety. Other 
studies have also reported that low CD4 count was a risk factor psychiatric morbidity [22-24]. This may be because patients with lower CD4 count are probably having more symptoms of HIV infection and consequently more emotional and physical disability. The high rate of depression among patients who do not know the HIV status of their spouses may be due to the constant worrying of these patients about their infection and perceived consequences of informing their partners about their HIV status [25].

Our study has some limitations as depressive and anxiety disorders often change with time, hence a snapshot analysis might not give exact degree of the condition. However, the advantage of a non-exposed control group helped assess the extent in the general population.

\section{Conclusion}

The prevalence of depression and anxiety is high among PLHIV and could present in a subtle manner. A routine screening for depressive and anxiety symptoms is recommended with a proper integration of mental health services into HIV care to give a comprehensive management to all HIV patients.

\section{Conflicts of Interest}

The authors declare no competing interests.

\section{References}

1. UNAIDS (2017) Global AIDS Update 2017. AIDS info website.

2. Owe-Larsson B, Sall L, Salamon E, Allgulander C (2009) HIV infection and psychiatric illness. Afr J Psychiatry 12: 115-128.

3. Chandra PS, Desai G, Ranjan S (2005) HIV \& psychiatric disorders. Indian J Med Res 121: 451-467.

4. Brandt C, Zvolensky MJ, Woods SP, Gonzalez A, Safren SA, et al. (2017) Anxiety symptoms and disorders among adults living with HIV and AIDS: A critical review and integrative synthesis of the empirical literature. Clin Psychol Rev 51: 164-184.

5. Nakimuli-Mpungu E, Bass JK, Alexandre P, Mills EJ, Musisi S, et al. (2012) Depression, alcohol use and adherence to antiretroviral therapy in sub-Saharan Africa: a systematic review. AIDS Behav 16: 2101-2118.

6. Sale S, Gadanya M (2008) Prevalence and factors associated with depression in HIV/AIDS patients aged 15-25 years at Aminu Kano teaching hospital, Nigeria. J Child Adolesc Ment Health 20: 95-99.

7. Igie I, Udoh M (2011) Prevalence of depression in HIV/AIDS patients, Lagos state university hospital (LUTH), Lagos, Nigeria. International AIDS society, 6th IAS conference on HIV Pathogenesis, Treatment and Prevention. Rome, Italy.

8. Tesfaw G, Ayano G, Awoke T, Assefa D, Birhanu Z, et al. Prevalence and correlates of depression and anxiety among patients with HIV on-follow up at Alert Hospital, Addis Ababa, Ethiopia. BMC Psychiatry 16: 368.
9. Elbadawi A, Mirghani H (2017) Depression among HIV/AIDS Sudanese patients: a cross-sectional analytic study. Pan Afr Med J 26: 43.

10. Olagunju AT, Adeyemi JD, Ogbolu RE, Campbell EA (2012) A Study on Epidemiological Profile of Anxiety Disorders Among People Living with HIV/AIDS in a Sub-Saharan Africa HIV Clinic. AIDS Behav 16: 2192-2197.

11. Adewuya AO, Afolabi MO, Ola BA, Ogundele OA, Ajibare AO, et al. (2008) Relationship between depression and quality of life in persons with HIV infection in Nigeria. Int J Psychiatry Med 38: 43-51.

12. Olisah V, Baiyewu O, Sheikh TL (2010) Adherence to highly active antiretroviral therapy in depressed patients with HIV/AIDS attending a Nigerian university teaching hospital clinic. Afr J Psychiatry 13: 275-279.

13. Ekiti State (2016) List of Nigerian States by Population.

14. Raosoft Inc (2016) Raosoft Sample Size Calculator Seattle. USA.

15. Bjelland I, Dahl AA, Haug TT, Neckelmann D (2002) The validity of the Hospital Anxiety and Depression Scale: An updated literature review. J Psychosom Res 52: 69-77.

16. Yunusa MA, Obembe A, Ibrahim T, Njoku CH (2011) Prevalence and specific psychosocial factors associated with substance use and psychiatric morbidity among patients with HIV infection at Usmanu Danfodiyo university teaching hospital, Sokoto state, Nigeria. Afr J Drug Alcohol Stud 10: 11-16.

17. Amiya RM, Poudel KC, Poudel-Tandukar K, Pandey BD, Jimba M (2014) Perceived family support, depression, and suicidal ideation among people living with HIV/AIDS: A cross- sectional study in the Kathmandu Valley, Nepal. PLoS One 9: e90959.

18. Rodkjaer L, Laursen T, Balle N, Sodeman M (2010) Depression in patients with HIV is under-diagnosed: a cross-sectional study in Denmark. HIV Med 11: 46-53.

19. Olley BO, Seedat S, Nei DG, Stein DJ (2004) Predictors of major depression in recently diagnosed patients with HIV/AIDS in South Africa. AIDS Patient Care STDs 18: 481-487.

20. Reif S, Proeschold-Bell RJ, Yao J, LeGrand S, Uehara A, et al. (2013) Three types of self-efficacy associated with medication adherence in patients with co-occurring HIV and substance use disorders, but only when mood disorders are present. J Multidiscip Healthc 229-237.

21. Kaharuza FM, Bunnell R, Moss S, Purcell DW, Bikaako-Kajura W, et al. (2006) Depression and CD4 Cell Count Among Persons with HIV Infection in Uganda. AIDS Behav 10: 105-111.

22. Kitshoff C, Campbell L, Naidoo SS (2012) The association between depression and adherence to antiretroviral therapy in HIV-positive patients, KwaZulu-Natal, South Africa. Afr Fam Pr 54: 145-150.

23. Akena D, Musisi S, Joska J, Stein DJ (2012) The Association between Aids Related Stigma and Major Depressive Disorder among HIV-Positive Individuals in Uganda. PLoS One 7: e48671.

24. Akena DH, Musisi S, Kinyanda E (2010) A comparison of the clinical features of depression in HIV-positive and HIV-negative patients in Uganda. Afr J Psychiatry 13: 43-51.

25. Olley BO, Seedat S, Stein DJ (2006) Persistence of psychiatric disorders in a cohort of HIV/AIDS patients in South Africa: A 6-month follow-up study. J Psychosom Res 61: 479-484. 